\title{
Los servicios públicos locales en el Perú: una aproximación a su caracterización jurídica
}

\section{The local public services in Perú: a legal characterization}

\author{
Diego Zegarra Valdivia \\ Pontificia Universidad Católica del Perú (Perú) \\ ORCID: https://orcid.org/0000-0002-8901-1026 \\ dzegarra@pucp.pe
}

\section{NOTA BIOGRÁFICA}

Doctor en Derecho por la Universidad de Alicante. Profesor Principal de Derecho Administrativo de la Pontificia Universidad Católica del Perú, donde es Coordinador del Área de Derecho Administrativo y del Grupo de Investigación en Derecho Administrativo (GIDA). Sus líneas de investigación son: procedimiento administrativo, servicios públicos, actividad de fiscalización, potestad sancionadora, datos personales y ordenación del territorio.

\section{RESUMEN}

El presente es un estudio en el que se pasa revista de la configuración de los municipios democráticos en el Perú, se analiza la evolución del régimen jurídico de los servicios públicos prestados en el ámbito local y se efectúa una aproximación a la caracterización jurídica los mismos.

\section{PALABRAS CLAVE}

Servicios públicos locales; función pública; función administrativa; municipalidades; democracia; ordenamiento jurídico peruano.

\begin{abstract}
This is a study in which the configuration of democratic municipalities in Peru is reviewed, the evolution of the legal regime of public services provided at the local level is analyzed and an approximation is made to their legal characterization.
\end{abstract}

\section{KEYWORDS}

Local public services; public function; municipalities; democracy; peruvian legal order.

\section{SUMARIO}

1. INTRODUCCIÓN. 2. EL PROCESO DE CONSTRUCCIÓN DE LOS MUNICIPIOS DEMOCRÁTICOS EN EL PERÚ. 2.1. LOS CABILDOS EN LA ETAPA VIRREINAL. 2.2. LOS MUNICIPIOS DURANTE LA ETAPA REPUBLICANA. 2.3. EL SURGIMIENTO DE LOS MUNICIPIOS DEMOCRÁTICOS EN 1963. 3. EVOLUCIÓN DEL RÉGIMEN JURÍDICO DE LOS SERVICIOS PÚBLICOS LOCALES EN EL PERÚ. 3.1. TRATAMIENTO CONSTITUCIONAL DE LOS SERVICIOS PÚBLICOS LOCALES. 3.2. LA EVOLUCIÓN DEL MARCO LEGAL DE LOS SERVICIOS PÚBLICOS LOCALES. 4. LOS SERVICIOS PÚBLICOS LOCALES EN EL PERÚ: CARACTERIZACIÓN JURÍDICA 5. LAS ACTIVIDADES COMPRENDI- 
DAS COMO SERVICIOS PÚBLICOS LOCALES EN EL ORDANAMIENTO JURÍDICO PERUANO. 5.1. EL SERVICIO DE LIMPIEZA PÚBLICA. 5.2. LOS SERVICIOS DE SANEAMIENTO. 5.3. EL SERVICIO DE ATENCIÓN PRIMARIA DE SALUD. 5.4. LOS SERVICIOS EDUCATIVOS. 5.5. LOS SERVICIOS DE TRÁNSITO, VIABILIDAD Y TRANSPORTE PÚBLICO. 5.6. SERVICIOS DE SEGURIDAD CIUDADANA. 5.7 OTRAS ACTIVIDADES CALIFICADAS COMO SERVICIOS PÚBLICOS LOCALES. 6. CONCLUSIONES. 7. BIBLIOGRAFÍA. 7.1. DOCTRINA. 7.2. LEGISLACIÓN REVISADA. 7.3. JURISPRUDENCIA.

\section{INTRODUCCIÓN1}

Las instituciones municipales en Iberoamérica han tenido mecanismos de designación directa de sus autoridades dependientes directamente de la voluntad de los gobiernos nacionales y es en las últimas décadas del siglo XX, con la consolidación de los sistemas democráticos, que se ha dado paso a la elección democrática de sus autoridades municipales.

Es en este contexto, que se ha desarrollado la prestación de servicios públicos locales, actividades, cuya caracterización jurídica es el principal objeto de estudio en el presente trabajo.

En base al objetivo planteado, la primera sección de este estudio introductorio está dedicado a describir el proceso de configuración de los municipios democráticos en el Perú, seguida luego de un análisis de la evolución del régimen jurídico de los servicios públicos en el Perú, tanto en su tratamiento constitucional como en la evolución de su régimen legal.

La tercera sección está dedicada a la caracterización jurídica del concepto de servicios públicos locales plasmado en el ordenamiento jurídico peruano con la finalidad de advertir sus particularidades y los aspectos que la distinguen de otras categorías jurídicas. Finalmente, en la cuarta sección se evalúan a las actividades calificadas por la vigente Ley 27972, Ley Orgánica de Municipalidades («LOM») como servicios públicos locales para establecer su naturaleza jurídica y determinar si las mismas son propias de las función prestacional que desarrollan las corporaciones locales.

\section{EL PROCESO DE CONFIGURACIÓN DE LOS MUNICIPIOS DEMOCRÁTICOS EN EL PERÚ}

\subsection{Los cabildos en la etapa virreynal}

Durante esta etapa, las autoridades locales eran designadas por el mismo Virrey y, en casos excepcionales, por nombramiento directo del Rey de España. Así, la primera evidencia histórica de designación de autoridades locales se plasma en el primer cabildo celebrado por Francisco Pizarro, el 22 de enero de 1535, quien designó al primer alcalde de la ciudad, el conquistador andaluz Nicolás de Rivera y Laredo conocido como «El Viejo» (Prescott, 2017).

Posteriormente, los ayuntamientos se organizaron bajo la figura de los repartimientos y encomiendas a partir de 1569 hasta el inicio de las reformas borbónicas que dieron lugar a la instalación de las intendencias en el siglo XVIII.

Esta estructura absolutista se mantuvo hasta el 31 de octubre de 1812, ya que, el Virrey Abascal, en razón a los preceptos de la Constitución de Cádiz, promulgada por las Cortes Generales de España en 1812, llevó a cabo las primeras elecciones municipales para elegir a dos alcaldes, dieciséis regidores y dos procuradores síndicos, las cuales se prolongaron hasta el año 1813 (Aljovín, 2016).

Las parroquias y los locales donde se realizaron las votaciones eran el Sagrario de la Catedral (Convento de La Merced), Huérfanos (Convento de San Juan de Dios), Santa Ana (Colegio de San Fernando), San Lázaro (Convento de San Francisco de Paula), San Sebastián (Convento de Santo Domingo) (Chiaramonti, 2016).

\subsection{Los municipios durante la etapa republicana}

El mecanismo de designación directa de las autoridades locales se mantuvo, inclusive, con la proclamación de la independencia del Perú en 1821, ello por previsión del propio Estatuto Provisional del 8 de octubre

1 La presente investigación se enmarca dentro de las actividades de la Línea de Investigación en Servicios Públicos y su elaboración contó la colaboración de Gianpierre Valverde Encarnación. 
de 1821, el mismo que dispuso que las municipalidades subsistirían con las misma organización y bajo el gobierno de las mismas autoridades que habían sido designadas en la colonia (López y Aljovín, 2018).

Con la promulgación de la primera Constitución Política del Perú de 1823 se incorporó en los artículos 138 y 139 la figura de los municipios y la forma de elección de sus autoridades por colegios electorales de parroquia, respectiamente. Posteriormente, las constituciones políticas de 1826 en sus artículos 128 y 129 y 1828 en sus artículos 140 y 143, conservaron la referencia a las municipalidades y su forma de elección como se había dictado en la Constitución de 1823 (García, 2016).

Con la aprobación de la Constitución Política de 1834, se mantiene la disposición referida a los entes municipales en su artículo 137 y vinculado a la elección de sus autoridades se dictó la Ley Órgánica de Elecciones y la Ley orgánica de municipalidades en el mismo año (López y Aljovín, 2018). En las sucesivas constituciones políticas de 1839, 1856, 1860 y 1867, es posible observar previsiones normativas respecto de los municipios y los mecanismos de elección de sus autoridades (García, 2016).

Posteriormente, bajo la vigencia de la Constitución política de 1920, fueron aprobados dos importantes cuerpos normativos. El primero fue la Ley N. ${ }^{\circ} 5644$, que autorizó el nombramiento de municipalidades provisionales en 1927; y, el segundo fue la Ley N..$^{\circ}$ 7482, que autorizó al Poder Ejecutivo a nombrar autoridades municipalidades provisionales mientras se realizaban las elecciones de 1932 (López y Aljovín, 2018).

Este citado texto constitucional fue sustituido por la Constitución de 1933 y durante su vigencia se dictó Ley N. ${ }^{\circ}$ 10233, de 4 de setiembre de 1945, que dispuso el establecimiento de Juntas Municipales Transitorias elegidas por Asambleas Electorales Municipales; la Ley N. ${ }^{\circ} 10537$, de 6 de abril de 1946, que dispuso que la administración comunal se ejercerá por las Juntas Municipales Transitorias, elegidas de acuerdo con la Ley N. ${ }^{\circ} 10233$ hasta que fue posible la instalación de los municipios elegidos popularmente; la Ley N. ${ }^{\circ} 10733$, Ley de Elecciones Municipales, de 5 de diciembre de 1946 que dispuso por primera vez la constitución de los Concejos Municipales por sufragio directo y secreto, siendo las autoridades elegidas por tres años; la Ley N. ${ }^{\circ} 12391$, Ley que otorgó el voto femenino en 1955, de 17 de setiembre de 1955; y, la Ley N. ${ }^{\circ}$ 14669, Ley de Elecciones Municipales de 24 de setiembre de 1963, por la cual se aprueba la elección de autoridades locales elegidas con voto popular de carácter secreto y directo (García, 2016).

Lo que puede destacarse como característica de este período, es que si bien las sucesivas constituciones de un Estado peruano en formación incorporaron regímenes de elección de las autoridades de los municipios, su aplicación se vió limitada por la falta de estabilidad de los gobiernos nacionales y por la prevalencia de la designación directa de quienes tenía a su cargo los gobiernos locales.

\subsection{El surgimiento de los municipios democráticos en 1963}

El proceso de configuración de los municipios democráticos en el Perú tuvo como punto de partida la convocatoria realizada en el año 1963 por el Presidente Fernando Belaúnde Terry para elegir a los Concejos Municipales, denominación con los que el artículo 203 de la Constitución Política de 1933 -vigente en ese periodo- se refería a los gobiernos municipales (Tuesta, 2016).

Sin embargo, luego de las elecciones de autoridades municipales por voto popular y en elecciones con voto directo y secreto se vieron interrumpidas entre 1967 y 1980, por la instalación de la dictadura militar encabezada por Juan Velasco Alvarado, al inicio, y continuada por Francisco Morales Bermúdez.

No obstante, con el retorno de la democracia y la promulgación de la Constitución de 1979, ya en su segundo gobierno, nuevamente el Presidente Fernando Belaúnde Terry volvió a convocar en 1980 a elecciones municipales, teniendo como marco normativo el artículo 3 de la Ley N. ${ }^{\circ} 14669$, el cual disponía la elección de autoridades municipales provinciales y distritales (Tuesta, 2016).

Al amparo del artículo 4 de la citada Ley N. ${ }^{\circ} 14669$, todos los ciudadanos peruanos inscritos en el Registro Electoral del Perú gozaban del derecho de sufragio para las elecciones municipales, siendo el voto obligatorio, directo y secreto. El periodo de duración de los mandatos municipales, de acuerdo al artículo 7 , era de 3 años contados desde el primer día del año siguiente a las elecciones.

A patir del año 1980, se sucedieron ininterrumpidamente elecciones municipales cada 3 años hasta 1998, año en la que se publicó la Ley de Elecciones Municipales, publicada por la Ley N. ${ }^{\circ} 26864$, que amplió el mandato por cuatro años. Posteriormente, desde el año 2002, las elecciones municipales coinciden con las elecciones regionales, de esta forma, los procesos electorales se han llevado a cabo cada cuatro años hasta el último que se realizó en el 2018 (López y Aljovín, 2018; Tuesta, 2016). 


\section{EVOLUCIÓN DEL RÉGIMEN JURÍDICO DE LOS SERVICIOS PÚBLICOS LOCALES EN EL PERÚ}

La configuración del régimen jurídico de los servicios públicos locales en el ordenamiento jurídico peruano se ha construido a partir del tratamiento que se le ha dado a nivel constitucional y del contenido jurídico que fue previsto en la normativa que regula a las municipalidades.

\subsection{Tratamiento constitucional de los servicios públicos locales}

Una de las fuentes normativas que ha dotado de contenido a la expresión servicios públicos locales ha sido el marco constitucional peruano. Así, en la citada Constitución Política de 1823 es posible encontrar, por primera vez, la referencia al servicio público en el artículo 156 -inserto en el Capítulo I de la Sección Tercera-, el cual regula el rol de la Hacienda Pública en la actividad aduanera, disponiendo que «(...) las aduanas se situarán en los puertos de mar y en las fronteras, en cuanto sea compatible con la recta Administración, con el interés del Estado y del servicio público» (Congreso Constituyente, 1823).

Asimismo, es posible observar que en el texto de la Constitución de 1839, se le concede al Presidente de la República la atribución de «hacer en los reglamentos de hacienda y de comercio, con acuerdo del Consejo de Estado, las alteraciones convenientes al servicio público, dando cuenta al Poder Legislativo» (Zegarra, 2005).

De esta forma, el servicio público fue adquiriendo diversas connotaciones en función a la impronta que se daba en cada etapa histórica. Así, en el artículo 8 de la Constitución de 1860, se encuentran referencias a que «(...) No puede imponerse contribuciones sino en virtud de una ley, en proporción a las facultades del contribuyente y para el servicio público» (Convención Nacional, 1860).

Lo que se advierte de la revisión de las constituciones del siglo XIX, es que el significado del servicio público estaba vinculado con el ejercicio de la función pública y que todavía no se tenía noción sobre la existencia de servicios públicos locales o de la municipalización de determnadas actividades de carácter prestacional.

Es con la llegada del siglo xx y la promulgación de la Constitución de 1920, que el Estado peruano inicia un proceso de municipalización y nacionalización de determinadas actividades de carácter prestacional y que implicaban su publificación al consideradas de interés público, habilitándose al Estado a expropiar las empresas privadas que prestaban dichos servicios (Asamblea Nacional, 1920).

La intervención de Estado en actividades vinculadas con la satisfacción de un interés general se fortalece con la Constitución de 1979, dado que, se consagra en su artículo 113 que «el Estado ejerce su actividad empresarial con el fin de promover la economía del país, prestar servicios públicos y alcanzar los objetivos de desarrollo» (Asamblea Constituyente, 1979). Asimismo, a través de la previsión introducida en el inciso artículo 254 del referido texto constitucional, se hizo posible la distinción entre los servicios públicos vinculados a la Administración central de aquellos vinculados con los gobiernos locales, al otorgársele a las municipalidades competencias para «organizar, reglamentar y administrar los servicios públicos locales» (Asamblea Constituyente, 1979).

Esta distinción se mantuvo en la actual Constitución de 1993, donde también se reconoce en los artículos 119, 192 y 195 que hay un esquema descentralizado de regulación, gestión y administración de los servicios públicos en los ámbitos central, regional y local (Congreso Constituyente Democrático, 1993).

De esta forma, de la revisión de los textos constitucionales, es posible afirmar que el reconocimiento de los servicios públicos locales ha seguido un proceso que actualmente permite considerar a los mismos como actividades cuya titularidad y gestión le han sido atribuidas a las municipalidades, como entes públicos de nivel descentralizado.

\subsection{La evolución del marco legal de los servicios públicos locales}

Como ha sido posible advertir, el servicio público ha estado presente en marco constitucional peruano desde los primeros años de la fundación de la República siendo extensiva su presencia en la legislación, pero sin acaso tener el contenido y la caracterización que actualmente tiene esta figura.

Al remontarse a la legislación más próxima a la formación del Estado peruano, se identifica el Decreto de 5 de junio de 1857, el Decreto de 27 de febrero de 1866 y la Resolución Legislativa de 5 de abril de 1873, que reglamentaban el régimen de prestación de los servicios de alumbrado de gas, de correos y la labor de 
los hospitales, respectivamente, los cuales concedían al particular un «privilegio de explotación sin señalarse de forma expresa que dicha concesión implicaba la prestación de estos servicios al público» (Zegarra, 2005).

Lo llamativo de esta regulación es el surgimiento del principio de continuidad asociado a los servicios públicos, ya que, como se estableció en el artículo 1 del Decreto de 11 de noviembre de 1850, se obligaba al prestador privado a comprometerse a «dar constantemente en todo tiempo para la cañería de fierro el agua necesaria para el consumo de la población del Callao (...)» (Zegarra, 2005).

Aún sin llegar a la noción actual del servicio público, la legislación fue acercándose a éste con la incorporación de elementos compositivos de esta categoría, como es el caso del término «utilidad pública». Esto se observa en la redacción del artículo $3^{\circ}$ de la Ley de 9 de noviembre de 1893 que declaraba de «utilidad pública la construcción de ferrocarriles».

Del mismo modo, sin llegar al reconocimiento expreso, se empezó a asimilar indirectamente la referencia a los servicios públicos locales como parte del proceso de municipalización que propició la creación de monopolios a nivel local en aquellos sectores considerados de interés general (Zegarra, 2005). Esto último quedó reflejado en el Decreto de 17 de julio de 1866, que adjudicó a la Municipalidad de Lima el camal general y el alumbrado público.

Esta tendencia continuó expandiéndose a más actividades como la generación eléctrica y el abastecimiento de agua potable, ya que las mismas pasaron a la titularidad de las municipalidades, dada la consideración del gobierno central de reconocerle un carácter eminentemente local.

Así, resulta ilustrativo lo dispuesto en la Ley N. ${ }^{\circ} 6188$ de 27 de abril de 1928 que declaró de utilidad pública la empresa de alumbrado eléctrico de Moquegua pasando de manos privadas a la gestión en el ámbito municipal. Esto último también se observa en el Decreto Ley N. ${ }^{\circ} 7241$ de 27 de julio de 1931 que dispuso que el servicio de agua potable de Arequipa pase al Consejo Municipal de esa ciudad.

Es de esta forma que la prestación de algunas actividades de interés general fue gestionándose por los gobiernos locales, quienes brindaban el servicio directamente a través de una dependencia administrativa. Sin embargo, este esquema de gestión cambió y se pasó a un modelo que implicaba la creación de una corporación adscrita a la Administración.

Este proceso empezó a gestarse a partir de la segunda mitad del siglo $x x$ bajo un diseño que implicaba la creación de personas jurídicas autónomas pero pertenecientes al Estado. Cabe referir, en ese sentido, a la Ley N. ${ }^{\circ} 13428$ de 1960, que creó la Corporación Departamental de Servicios Eléctricos de Lambayeque; entidad que tenía como objeto la conservación, mejoramiento y administración de los servicios de electricidad establecidos por las Municipalidades en el Departamento de Lambayeque.

Al iniciar la década de 1970, se experimentó un proceso de concentración de los servicios públicos, que provocó que los servicios públicos locales pasen a la gestión del gobierno central, lo que supuso la desmunicipalización de una serie de actividades prestacionales.

Esto se observa, por ejemplo, con la prestación de los servicios de electricidad que abandonaron la titularidad municipal y se concentraron en la empresa pública «Electricidad del Perú», como quedó dispuesto en el Decreto Ley N. ${ }^{\circ} 21906$ de 16 de agosto de 1977. Cabe señalar, por otro lado, que este proceso de desmunicipalización no fue total, porque se conservaron dentro del ámbito de los gobiernos locales los servicios de saneamiento, que continuaron siendo administradas y operadas por empresas municipales como sucede hasta la actualidad (Zegarra, 2005).

A partir de 1990, se produjo un proceso de liberalización y privatización que retrasó la vuelta en escena de la municipalización de los servicios públicos, ya que, el objetivo fue que el Estado abandone la prestación directa de estas actividades, a través de empresas estatales, para otorgarlas en gestión indirecta a empresas privadas (Cairampoma y Solar, 2010).

En los primeros años de la década pasada y de vuelta con el proceso de descentralización, en el Perú se retomó la discusión respecto de la importancia de delegar determinadas funciones a los gobiernos regionales y locales. Ello fue materializándose con la publicación de la Ley de Base de Descentralización, Ley $\mathrm{N} .{ }^{\circ} 27783$ que, en su artículo 42, inciso c), atribuye a las municipalidades competencias exclusivas para «(...) administrar y reglamentar los servicios públicos locales destinados a satisfacer necesidades colectivas de carácter local» (Congreso de la República, 2002).

Dentro de este mismo esquema, con la promulgación de la Ley 27.972, Ley Orgánica de Municipalidades se reconoce expresamente la titularidad municipal de determinadas actividades como servicios públicos locales, cuya gestión y prestación puede ser directa o indirecta «siempre que sea permitido por ley y que se asegure el interés de los vecinos, la eficiencia y eficacia del servicio y el adecuado control municipal» (Congreso de la República, 2003). 
Las actividades previstas en el artículo 73 de la citada LOM como servicios públicos locales son: a) el saneamiento ambiental, salubridad y salud; b) tránsito, circulación y transporte público; c) educación, cultura, deporte y recreación; d) programas sociales, defensa y promoción de derechos de ciudadanos; e) seguridad ciudadana; f) abastecimiento y comercialización de productos y servicios; g) registros civiles; h) promoción del desarrollo económico local para la generación de empleo; i) Establecimiento, conservación y administración de parques zonales, parques zoológicos, jardines botánicos, bosques naturales; j) otros servicios públicos no reservados a entidades de carácter regional o nacional.

Respecto a este conjunto de actividades previstas en la LOM, cabe resaltar que no es posible encontrar características homogéneas entre ellas que permitan caracterizarlas como un servicio público, por lo que es necesario analizar sus aspectos individuales para determinar su consideración como tales, independientemente de que el legislador les haya querido otorgar dicho carácter.

\section{LOS SERVICIOS PÚBLICOS LOCALES EN EL PERÚ: CARACTERIZACIÓN JURÍDICA}

Previamente a la caracterización de los servicios públicos locales, es necesario explicar el concepto de servicios públicos adoptado en ordenamiento jurídico peruano. Al respecto, debemos señalar que no se ha configurado en la Constitución de 1993 ni en las leyes sectoriales un concepto uniforme de servicio público. Ha sido el Tribunal Constitucional (2005) el que en una serie de pronunciamientos ha declarado que los servicios públicos tienen una naturaleza esencial para la comunidad, deben tener continuidad en el tiempo, brindarse de manera regular y su acceso se da en condiciones de igualdad.

Sobre estos elementos es posible colegir que los servicios públicos en el Perú son actividades de carácter económico o social de especial trascendencia para el país porque buscan satisfacer necesidades públicas para alcanzar el bienestar general, y cuya organización y prestación pueden realizarse de forma directa o indirecta por la Administración bajo un régimen de derecho público.

El ordenamiento jurídico peruano establece dos requisitos para que una actividad sea calificada como servicio público: su carácter material y su carácter formal (Ramón, 2016). Respecto al carácter material, cabe indicar que se refiere a la naturaleza esencial de la actividad económica o social para la comunidad Zegarra (2005), estando comprendidos servicios como la electricidad, el saneamiento, las telecomunicaciones, la salud o la educación. Es decir, actividades que por su propia finalidad son imprescindibles en una sociedad.

Mientras que, por el lado del carácter formal, se refiere a la necesidad de que dichas actividades hayan obtenido esa calificación a través de una norma de rango legal Zegarra (2005).

En lo que respecta a los servicios públicos en el ámbito local, el numeral 5 del artículo 195 de la Constitución peruana de 1993 dispone que los gobiernos locales son competentes para organizar, reglamentar y administrar los servicios públicos que sean de su responsabilidad, de acuerdo con el siguiente texto:

Artículo 195.- Los gobiernos locales promueven el desarrollo y la economía local, y la prestación de los servicios públicos de su responsabilidad, en armonía con las políticas y planes nacionales y regionales de desarrollo. son competentes para: (...) 5. Organizar, reglamentar y administrar los servicios públicos locales de su responsabilidad (...).

De igual modo, el numeral c) del artículo 42 de la Ley de Bases de la Descentralización establece que son competencias municipales exclusivas las de «administrar y reglamentar los servicios públicos locales destinados a satisfacer necesidades colectivas de carácter local».

En lo que respecta a la LOM, en su artículo 73 prevé que las municipalidades, provinciales o distritales, asumen competencias y ejercen funciones en materia de servicios públicos locales, específicamente en el área de saneamiento ambiental, salubridad y salud; y, en los artículos del 78 al 87 se mencionan las funciones que deben ejercer en virtud de dichas materias, como es la de proveer el servicio de limpieza pública.

Para el caso de los servicios públicos locales, existe entonces una reserva prestacional a favor de las Municipalidades, toda vez que la propia LOM establece que estas actividades son de responsabilidad de tales instancias de gobierno, por lo que en muchos casos dichos servicios son prestados en forma directa siendo los mismos retribuidos a través de los arbitrios (Huapaya 2015).

Resulta necesario, como parte de esta caracterización, efectuar un deslinde de lo que se entiende por servicios públicos locales con aquellas actividades que soponen el ejercicio de función administrativa o función pública -sin aludir al empleo público- ya que en el Perú es frecuente la confusión que se produce entre unas y otras. 
Sobre esto último, resulta acertado lo expresado por Ariño (2011) cuando considera que la función pública o función administratica se desarrolla para la consecución de los fines esenciales del Estado y ello implica naturalmente una actividad soberana que en ningún caso puede quedar a cargo de la iniciativa privada, manifestándose, por tanto, a través de la actividad legislativa, judicial y administrativa (defensa, policía, fiscal y tributaria). Es claro entonces que elementos característicos de los servicios públicos en el ámbito local no pueden asociarse con aquellos que son propios de la función administrativa porque esta última no tiene carácter prestacional, sino que deriva del ejercicio del ius imperium del Estado, no puede ser explotable económicamente, y como actividad, beneficia a la colectividad en su conjunto.

\section{LAS ACTIVIDADES COMPRENDIDAS COMO SERVICIOS PÚBLICOS LOCALES EN EL ORDENAMIENTO JURÍDICO PERUANO}

El glosado numeral 2 del artículo 73 de la LOM ha previsto un conjunto de actividades calificadas como servicios públicos locales. Sin embargo, no todas las actividades nombradas en este precepto, necesariamente califican dentro de la categoría de servicio público, a pesar de que tengan esta denominación legal.

Por ello, es importante identificar qué actividades pueden ser consideradas dentro de la noción de servicios públicos locales, porque independientemente a que la ley le otorgue la titularidad del servicio a los municipios, otra cosa es que los mismos tengan competencia sobre la materia específica de la actividad (Del Guayo, 2004).

\subsection{El servicio de limpieza pública}

En el artículo 80.3 de la LOM se establece como una función de las municipalidades distritales la provisión del servicio de limpieza pública como parte de su actividad prestacional dentro de su circunscripción geográfica.

El servicio de limpieza pública, en ese sentido, está compuesto por el servicio de barridos de calles y el servicio de recolección de residuos sólidos y tiene por finalidad conservar la salubridad del municipio donde operan (Ramón, 2016).

En el Perú, el servicio de limpieza pública es una prestación brindada por los gobiernos locales a cambio de una contraprestación obtenida mediante arbitrios municipales que son determinados individualmente a cada vecino de un distrito en función a criterios que fueron establecidos por el Tribunal Constitucional (2004) como el uso y el tamaño del predio.

De modo que, se puede concluir por las características de esta actividad, que se trata de un servicio público municipal dado que es una actividad económica dirigida a la utilidad general del público e indispensable para la vida social porque previene los riesgos para la salud, protege al ambiente y trae consigo una mejora en la calidad de vida de la población (Ramón, 2016).

Su gestión puede ser directa o indirecta, ya que, en muchos casos, las municipalidades distritales optan por prestar el servicio directamente a través de una oficina o de una empresa municipal, o lo brindar indirectamente mediante la contratación de un concesionario que se haga cargo de los servicios a cambio de una contraprestación económica (Villar, 2017).

\subsection{Los servicios de saneamiento}

De la lectura del numeral 1 artículo 80.2 de la LOM, es posible identificar dentro de las competencias de las municipalidades provinciales la administración y reglamentar directa o por concesión el servicio de agua potable, alcantarillado y desagüe.

Asimismo, de acuerdo al artículo 4.3 del la Ley Marco de gestión y prestación de los servicios de saneamiento, promulgado por Decreto Legislativo N. ${ }^{\circ} 1280$, los gobiernos locales son los responsables de asegurar la prestación eficiente de los servicios de saneamiento usando los medios institucionales y económicos.

En el Perú, el servicio de saneamiento es brindado por las entidades prestadoras de servicios de saneamiento («EPS»). Estas son entidades que operan en el ámbito urbano y son constituidas con el único propósito de prestar servicios de saneamiento (Cairampoma y Villegas, 2016). Actualmente, existen 50 EPS, de las cuales 48 son empresas municipales, 1 es una Unidad Ejecutora administrada por el OTASS y la otra es la empresa SEDAPAL administrada por el Gobierno Central. 
De esa manera, los servicios de saneamiento cumplen con las características que la califican como servicio público, tal como es reconocido en el artículo III de la Ley Marco de gestión y prestación de los servicios de saneamiento donde se señala que estos servicios son servicios públicos esenciales por su impacto en la salud de la población, el ambiente y el desarrollo económico.

\subsection{El servicio de atención primaria de salud}

El inciso 2.5 del artículo 80 de la LOM le confiere competencias a las municipalidades para gestionar la atención primaria de salud, así como construir y equipar postas médicas, botiquines y puestos de salud en los centros poblados que los necesiten; así como, realizar campañas locales sobre medicina preventiva, primeros auxilios, educación sanitaria y profilaxis.

En linea con lo antes expresado, las municipalidades no tienen la titularidad de la prestación de los servicios médicos, ya que, son el Ministerio de Salud y los gobiernos regionales, quienes sí tienen a su responsabilidad la prestación de estos servicios.

De acuerdo con esto último el rol que cumplen las municipalidades solo involucra la realización de campañas, la gestión de la atención primaria a través de postas de salud y realizar el apoyo para la construcción y dotación de equipamiento para estos centros de atención primaria. De esta forma, como actividad, estamos frente a un servicio público social en el que los gobiernos locales tienen la obligación de organizar y gestionar de forma directa.

\subsection{Los servicios educativos}

En el Perú, la educación es una actividad que constituye un derecho fundamental y, «también un servicio público, dado que se trata de una prestación pública que explicita una de las funciones-fines del Estado, de ejecución por el propio Estado o por terceros bajo fiscalización estatal» (Tribunal Constitucional, 2005b).

En el ámbito de la normativa municipal, el artículo 82 de la LOM, dispone que las municipalidades tienen competencias para diseñar, ejecutar y evaluar el proyecto educativo de su jurisdicción, en coordinación con la Dirección Regional de Educación y las Unidades de Gestión Educativas a fin de contribuir en la política educativa regional y nacional. De esta forma, los gobiernos locales tienen competencia para gestionar la prestación del servicio de educación básica dentro de su jurisdicción.

Con el propósito de materializar el ejercicio de las referidas competencias, en el año 2006 se publicó el Decreto Supremo N. ${ }^{\circ}$ 078-2006-PCM, Plan Piloto de Municipalización de la Gestión Educativa de niveles educativos de inicial y primaria, el mismo que luego fue fortalecido a través del Plan de Municipalización de la Gestión Educativa y Lineamientos del Plan Piloto 2007, aprobado por la Resolución Ministerial N. ${ }^{\circ}$ 0031-2007-ED, cuyo objetivo fue descentralizar la prestación y gestión de la educación básica a las municipalidades.

Sin embargo, el proceso de municipalización de la gestión educativa se anuló y experimentó un proceso de centralización, ya que, los resultados obtenidos no fueron los esperados. Así, mediante la publicación del Decreto Supremo N. ${ }^{\circ}$ 022-2010-ED, que pone fin al Plan Piloto, el mismo que fue complementado posteriormente por la Ley de presupuesto público del año 2012.

De esa manera, tratándose del servicio público de educación y prestación en el ámbito de los gobiernos locales, se buscó que éstos ejercieran competencias respecto de su gestión y organización sin tener la titularidad sobre la actividad, sin embargo, los resultados desfavorables truncaron este intento de municipalización de la educación.

\subsection{Los servicios de tránsito, viabilidad y transporte público}

De acuerdo al artículo 81 de la LOM, las municipalidades tienen competencia para normar, regular, planificar el transporte terrestre, fluvial y lacustre a nivel local, así como normar y regular el servicio público de transporte.

Sin embargo, el precepto no le concede titularidad del servicio, sino que le otorga facultades de control y autorización para los particulares que deseen prestar el servicio de transporte público dentro de su ámbito geográfico.

Esto último se advierte de la lectura de la Ley 27.181, Ley General de Transporte y Tránsito Terrestre, conforme a la cual los gobiernos locales tienen competencia normativa, de gestión y de fiscalización en el 
ámbito del transporte público (Poole, 2016), lo que significa que las municipalidades no tienen competencia para prestar el servicio de transporte público, solo para gestionar su desarrollo y fiscalizar que los particulares lo realicen de manera eficiente y accesible.

Una situación excepcional se advierte en Lima y el Callao, ya que, estas competencias ya no le corresponden a los gobiernos locales de Lima o el Callao, sino que, mediante la Ley que crea la Autoridad de Transporte Urbano para Lima y Callao (ATU), Ley N. ${ }^{\circ} 30900$, se le otorgó esta potestad a la Autoridad de Transporte Urbano para Lima y el Callao.

\subsection{Servicios de seguridad ciudadana}

Respecto a las actividades consideradas como función administrativa de ámbito local es importante mencionar el caso del serenazgo. Pues bien, de acuerdo con el inciso 1 del artículo 85 de la Ley N. ${ }^{\circ} 27972$, Ley Orgánica de Municipalidades, se establece como función exclusiva de las municipalidades provinciales, establecer un sistema de seguridad ciudadana, con participación de la sociedad civil y de la Policía Nacional del Perú, y normar el establecimiento de los servicios de serenazgo de nivel distrital o de centros poblados en la jurisdicción provincial, de acuerdo a ley.

Por su parte, la Ley Orgánica de Gobiernos Regionales, y normas modificatorias, establece como competencia y función de dichos órganos de gobierno la seguridad ciudadana; así como dirigir el Comité Regional de Seguridad Ciudadana y formular las políticas en la materia, en concordancia con la política nacional formulada por el Consejo Nacional de Seguridad Ciudadana (CONASEC) y el Sistema Nacional de Seguridad Ciudadana (SINASEC).

Cabe indicar que el Ministerio del Interior es el ente rector del Sistema Nacional de Seguridad Ciudadana (SINASEC) ${ }^{2}$. Entre sus funciones se encuentran las de coordinar la cooperación de la Policía Nacional del Perú y las Municipalidades en materia de seguridad ciudadana, especialmente la articulación de los recursos humanos y logísticos de las Comisarías y los servicios de serenazgo para el patrullaje integrado, bajo comando y liderazgo operativo del Comisario, así como coadyuvar a la organización y capacitación de las juntas vecinales.

En este caso, se colige que el servicio de serenazgo, a pesar de su denominación de servicio público local, no cumple con las características para ser considerado como tal, ya que es una actividad proveniente del ius imperium del Estado que no que pueda ser prestada por los particulares y que, en cierto modo, implica el ejercicio de potestades punitivas.

\subsection{Otras actividades calificadas como servicios públicos locales}

Las otras actividades que la LOM prevé en el artículo 73.2 como servicios públicos locales como son los programas sociales, el abastecimiento y comercialización de productos y servicios, los registros civiles, la promoción del desarrollo económico local y el establecimiento, conservación y administración de parques zonales y zoológicos, sin embargo, no reúnen los requisitos de los servicios públicos locales.

A decir de Danós (2008), estas actividades son propias de la función administrativa que las municipalidades están obligadas a cumplir, y que si bien son denominadas como servicio públicos, lo cierto es que su ejecución deriva de las competencias que son atribuidas a los municipios en atención a las necesidades de la comunidad.

\section{CONCLUSIONES}

Hasta antes de 1963, los alcaldes y regidores eran nombrados directamente por el Gobierno Central. Por ello, es válido afirmar que el proceso de construcción de los municipios democráticos en nuestro país se inició en 1963 con la primera convocatoria a elecciones municipales. Sin embargo, este proceso se interrumpió por causa del golpe de estado perpetrado por las Fuerza Armadas al mando del General Velasco. El retorno de la democracia permitió reanudar las elecciones democráticas para elegir a las autoridades locales. Así, desde 1980 hasta la actualidad, los alcaldes y los regidores son elegidos por voto popular.

2 Constituye la autoridad técnica normativa de alcance nacional encargada de dictar normas, establecer los lineamientos y procedimientos relacionados con el diseño, la implementación y evaluación de las políticas de seguridad ciudadana y coordinar su operación técnica, así como las formas de articulación entre las diversas entidades involucradas. Es responsable del funcionamiento estructurado, articulado y descentralizado de las instituciones que conforman el Sistema Nacional de Seguridad Ciudadana. 
Respecto al tratamiento constitucional de los servicios públicos locales, cabe manifestar que no tuvo una referencia constitucional hasta la promulgación de la Constitución Política de 1979 en el Perú, la cual se mantiene en la Constitución de 1993 como parte de las competencias de las municipalidades.

En el plano legislativo, la noción de los servicios públicos -aplicable al ámbito local- ha experimentado diversos cambios en su concepción. Así, hemos observado que, a mediados del siglo XIX, se le asociaba a la función aduanera de la Administración. Luego fue tratada como una actividad de utilidad pública para, finalmente, llegar a concebirse como una actividad prestacional de carácter económico o social cuya titularidad está a cargo de un municipio.

Bajo esta definición, se examinaron las actividades previstas como servicios públicos de carácter local en el artículo 73.2 de la LOM, lo que permitió determinar que algunas de ellas, a pesar de tener esta denominación legal, no calificaban en sentido estricto como servicios públicos locales.

Así, a nuestro entender, los servicios de saneamiento y de limpieza pública cumplen con las características del servicio público local de carácter económico, ya que, son económicamente explotables e implican la prestación de una actividad de carácter esencial a una comunidad de vecinos insertos dentro del ámbito geográfico de competencia de una municipalidad distrital o provincial.

Por su lado, en materia de educación y salud, se advierte que estas actividades se insertan dentro de la calificación de servicio público local de carácter social, en la medida que las municipalidades tienen el deber funcional de ejecutar tales servicios que representan también derechos fundamentales de los vecinos.

En el caso del servicio de serenazgo y el servicio de transporte público, sus características nos llevan a calificarla como actividad propia de la función administrativa, ya que, es una actividad proveniente del ius imperium del Estado. Asimismo, no es una actividad pueda ser prestada por los particulares, dado que, solamente las municipalidades pueden brindar este servicio porque, en cierto modo, implican el ejercicio de potestades punitivas.

Finalmente en los casos de las actividades de abastecimiento, promoción de la cultura, programas sociales, registros civiles y establecimiento y conservación de parques zonales consideramos que también se trata de actividades derivadas del cumplimiento de las funciones administrativas de los gobiernos locales y cuya competencia les obliga a brindarlos a su comunidad.

\section{BIBLIOGRAFÍA}

\subsection{Doctrina}

ALJOVÍN, C. (2016): "Ocho verdades sobre las elecciones decimonónicas en el Perú", en ARAGÓN, J. (ed.): Participación, competencia y representación política. Lima (Perú): IEP.

BASADRE, J. (2005): Historia de la República del Perú [1822-1933]. Lima (Perú): El Comercio.

CAIRAMPOMA, A. \& SOLAR, G. (2010): El régimen legal del servicio universal de telecomunicaciones. El caso peruano del Fondo de Inversiones en Telecomunicaciones - FITEL. Lima (Perú): Adrus.

CHIARAMONTI, G. (2016): "Las elecciones del ayuntamiento constitucional en el Cuzco, 1813-1814", en O'PHELAN GODOY, S. (ed.): 1814: la junta de gobierno del Cuzco y el sur andino, págs. 99-128. Lima (Perú): Fondo Editorial de la PUCP.

DANÓS, J. (2008): "El régimen de los servicios públicos en la Constitución Peruana", en Revista Themis, núm. 55, págs. 255-264.

DE LA CUÉTARA MARTÍNEZ, J. M.; MARTÍNEZ LÓPEZ-MUÑIZ, J. M. \& VILLAR ROJAS, F. J. (2011): Derecho administrativo y regulación económica: liber amicorum profesor Doctor Gaspar Ariño Ortiz. Madrid: La Ley.

DELGADO DE LA FLOR, C. (2017): Deconstruyendo la municipalización de los servicios públicos: a propósito del análisis de la pertinencia legal de la creación de empresas municipales prestadoras del servicio público de distribución de gas natural por red de ductos a la luz del actual régimen económico peruano (Tesis de pregrado). Lima (Perú): Pontificia Universidad Católica del Perú.

DEL GUAYO, I. (2004): "La gestión de servicios públicos locales", en Revista de Administración Pública, núm. 165, págs. 87-133.

GARCÍA, D. (2016): Las constituciones del Perú. Lima (Perú): Fondo Editorial del JNE.

GIMENO, J. M. (2017): "La remunicipalización de servicios públicos locales: la necesaria depuración de conceptos y los condicionantes jurídicos desde la óptica del derecho europeo", en Cuadernos de Derecho Local, núm. 43, págs. 31-78.

HUAPAYA, R. (2015): "Concepto y Régimen Jurídico del Servicio Público en el Ordenamiento Público Peruano", en Revista lus Et Veritas, núm. 50, págs. 394-395. 
LÓPEZ, S. \& ALJOVÍN, C. (2018): Historia de las elecciones en el Perú: estudios sobre el gobierno representativo. Lima (Perú): IEP.

MARTÍNEZ-ALONSO, J. L. (2018): “Los debates sobre los servicios públicos locales: Estado de la cuestión”, en Revista Catalana de Dret Públic, núm. 57, págs. 72-96.

OCHOA, C. (2013): "El servicio público en la Constitución peruana de 1993", en Pensamiento constitucional, núm. 18, págs. 105-119.

POOLE, E. (2016): Rectificando las fallas del mercado: balance del proceso de implementación en Lima del Sistema Integrado de Transporte (SIT) y propuestas para su perfeccionamiento bajo un régimen de servicio público (Tesis de pregrado). Lima (Perú): Pontificia Universidad Católica del Perú.

PRESCOTT, W. (2017): Historia de la conquista del Perú: con observaciones preliminares sobre la civilización de los Incas. Lima (Perú): Ediciones El Lector.

RAMÓN, M. (2016): La naturaleza jurídica de la actividad de limpieza pública a cargo de los gobiernos locales (Tesis de pregrado). Lima (Perú): Pontificia Universidad Católica del Perú.

TORNOS, J. (2017): "Liberalización de servicios públicos locales y modalidades de actuación local en los sectores liberalizados", en Revista de Estudios de la Administración Local y Autonómica (REALA). Nueva Época, núm. 7 , págs. 103-114. DOI: https://doi.org/10.24965/reala.v0i7.10429.

TUESTA, F. (2016): Partidos políticos y elecciones: representación política en América Latina. Lima (Perú): PNUD.

VILLAR, F. (2017): "Los contratos para la prestación conjunta de servicios públicos locales", en Revista de Estudios de la Administración Local y Autonómica (REALA). Nueva Época, núm. 7, págs. 5-18.

VILLEGAS, P. \& CAIRAMPOMA, A. (2016): "El acceso universal al agua potable. La experiencia peruana", en Revista Derecho PUCP, núm. 76, págs. 229-250. DOI: https://doi.org/10.24965/reala.v0i7.10420.

ZEGARRA, D. (2005): El servicio público: Fundamentos. Lima (Perú): Palestra.

\subsection{Legislación revisada}

ASAMBLEA NACIONAL (1920): Constitución Política de 1920. Lima, 18 de enero.

CONGRESO CONSTITUYENTE (1823): Constitución Política de 1823. Lima, 12 de noviembre.

ASAMBLEA CONSTITUYENTE (1979): Constitución Política de 1979. Lima, 12 de julio.

CONGRESO CONSTITUYENTE DEMOCRÁTICO (1993): Constitución Política de 1993. Lima, 29 de diciembre.

CONGRESO DE LA REPÚBLICA DEL PERÚ (2018): Ley que crea la Autoridad de Transporte Urbano para Lima y Callao (ATU), Ley N. ${ }^{\circ}$ 30900. Lima, 28 de diciembre.

CONGRESO DE LA REPÚBLICA DEL PERÚ (2004): Ley del sistema de acreditación de los gobiernos regionales y locales, Ley N. ${ }^{\circ} 28273$. Lima, 9 de julio.

CONGRESO DE LA REPÚBLICA DEL PERÚ (2003): Ley Orgánica de Municipalidades, Ley N.² 27972. Lima, 27 de mayo.

CONGRESO DE LA REPÚBLICA DEL PERÚ (2002): Ley de Bases de la Descentralización, Ley N. ${ }^{\circ} 27783$. Lima, $^{20}$ de julio.

CONGRESO DE LA REPÚBLICA DEL PERÚ (1999): Ley General de Transporte y Tránsito Terrestre, Ley N.²7181. Lima, 8 de octubre.

CONVENCIÓN NACIONAL (1860): Constitución Política de 1860. Lima, 13 de noviembre.

PRESIDENCIA DE LA REPÚBLICA (2016): Ley Marco de la gestión y prestación de los servicios de saneamiento, Decreto Legislativo N. ${ }^{\circ}$ 1280. Lima, 29 de diciembre de 2016.

\subsection{Jurisprudencia}

TRIBUNAL CONSTITUCIONAL DEL PERÚ (2005a): Sentencia recaída en el Expediente N. ${ }^{\circ}$ 00034-2004-PI/TC. Lima, 15 de febrero.

TRIBUNAL CONSTITUCIONAL DEL PERÚ (2005b): Sentencia recaída en el Expediente $N^{\circ}$ 04232-2004-AA/TC. Lima, 3 de marzo.

TRIBUNAL CONSTITUCIONAL DEL PERÚ (2004): Sentencia recaída en el Expediente N. ${ }^{\circ}$ 00041-2004-PI/TC. Lima, 11 de noviembre.

TRIBUNAL CONSTITUCIONAL DEL PERÚ (2003): Sentencia recaída en el Expediente N. ${ }^{\circ}$ 0008-2003-AI/TC. Lima, 11 de noviembre. 